\title{
UK government's support 'essential' for exploitation of superconductivity
}

London. Less than a month after the British government outlined a new strategy for linking science to wealth creation, its strategy is being tested by demands for support for the development of new products based on recent advances in superconductivity.

Leading researchers, in both universities and industry, claim that extra government support is essential to bridge the persisting gap between the technological and commercial potential of superconductivity. Without it, they argue, British companies will

\section{IMAGE UNAVAILABLE FOR COPYRIGHT REASONS}

\section{A superconducting filter (right) could replace the bulkier conventional filter (left) in picking up radio signals from satellites.}

inevitably fall behind their competitors in the United States and Japan, many of whom were able to benefit from substantial government backing.

But the Department of Trade and Industry (DTI) has decided to axe the Advanced Technology Programme (ATP), under which it has spent $£ 8$ million over five years on the applications of superconductivity. That follows from the department's decision to shift the focus of its support for innovation towards the mechanisms of technology transfer, and thus away from direct backing for new developments.

Calls for government action have been stimulated by visits to the United States of two teams of British physicists, organized by the Institute of Physics and funded by
DTI. One team looked at developments in the power engineering applications of both low- and high-temperature superconductivity, the other at their applications to electronics systems.

Both teams were impressed by what they had been shown at government, university and industrial research laboratories. They were also convinced that, even at a lower level of funding, British achievements remain comparable with those in the United States: "the green shoots are there," says Gordon Donaldson, professor of physics at the University of Strathclyde and the leader of the electronics team.

But both teams also argue in their separate reports, published by the institute last week, that while the US government continues to provide full support for many industrial research projects - currently spending about $\$ 400$ million a year - the recent rearrangement of funding for technology casts doubt on the prospects of a similar type of support for superconductivity in Britain.

The main need at present, according to superconductivity researchers, is for backing for a number of "demonstrator" projects to prove the commercial viability of products incorporating superconducting technology, for example in passive microwave devices that can be used for satellite communications.

But each of the more obvious routes forward outlined in the government's white paper (policy statement) last month presents difficulties. For example, research groups in at least two large companies - ICI and GEC have already achieved significant results in areas such as the production of superconducting thin films and logic devices. Yet in neither case is the parent company so far prepared to make a unilateral commitment sufficient to turn these developments into marketable products.

The strategy popular in the United States of using small start-up companies as the cutting edge of product innovation is widely seen as more difficult in Britain, both because of the greater difficulty in raising venture capital and the relative lack of the government contracts on which many startup companies rely.

One significant source of funding is the Science and Engineering Research Council (SERC), which has itself been funding a major superconductivity research programme. But moves to shift more SERC funds (or, more particularly, those of its planned successor, the Engineering and
Physical Sciences Research Council) into product development are likely to meet resistance from other scientists, arguing that it would inevitably lead to reduced funding for basic research.

And although the government is encouraging companies to collaborate at the European level through programmes organized by the Commission of the European Communities in Brussels, researchers in the field argue that the 12-18 months required for such an initiative to get off the ground is too long to meet the immediate needs of British industry.

The solution being put to the government is that it should back a three-year joint initiative, involving the DTI, the SERC, the Defence Research Agency and industrial participants, and costing an estimated $£ 2$ million a year over this period. The programme would aim at setting up intercompany teams with the goal of targeting specific market sectors.

Donaldson, whose own work pioneering the medical applications of superconducting detector coils is already being taken up by US companies, argues that such a programme is essential if a British superconductivity industry is to take off. "At present, the industry is at a crisis point; we must act now," he says.

So far, there has been no positive response from the DTI, although officials say that they are keeping the situation "under observation" - and point out that potential avenues for continued funding still exist through, for example, the LINK scheme, by which it sponsors joint projects between industrial and academic researchers.

The SERC has reaffirmed its own support for superconductivity research. The topic figured prominently during a two-day meeting of its materials commissions last week, which decided to maintain funding for such research at its current level of about $£ 3.4$ million a year.

But in a situation where everyone seems to be waiting to see who blinks first, fears are growing that superconductivity in general, and high-temperature superconductivity in particular - both fields to which Britain has made fundamental scientific and technological contributions - could join the list of technologies that end up being exploited elsewhere.

"Superconductivity is like a child which is growing into adolescence," says David Caplin, professor of physics at Imperial College, London. "It has grown through an immensely successful childhood stage, and has already shown its future potential; but it still requires parental support if that potential is to be realized." 